\title{
Cannabis money opens new opportunities, and ethical dilemmas, for medical research
}

\author{
— Cite as: CMAJ 2019 February 19;191:E205-6. doi: 10.1503/cmaj.109-5712
}

Posted on cmajnews.com on Jan. 31, 2019.

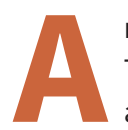

research partnership between The Lung Association of Ontario and Tetra Bio-Pharma, a drug company focused on medicinal cannabis, has raised questions about whether it is appropriate for health-focused charities and researchers to work with companies selling a product that is smoked.

Tetra is running clinical trials for a smokable medical cannabis product to relieve cancer pain. The company also supports a cannabis health research chair at the University of New Brunswick.

The Lung Association, like most health charities, scientific societies and academic institutions, won't accept funding from tobacco companies, and cannabis companies should be treated the same way, said Grace Parraga, a lung researcher at Western University. "I don't think it's wise to partner with something that's mainly smoked or vaped," she said, adding that there has been little attention paid to the health risks of inhaling cannabis smoke.

But The Lung Association of Ontario says the partnership with Tetra is different because cannabis, unlike tobacco, has medicinal applications. "Research is needed to fully understand the utility of medical cannabis and cannabis-derived pharmaceuticals as viable options for chronic pain management and the treatment of a variety of conditions," the association said in a statement sent to members of the Ontario Thoracic Society and Ontario Respiratory Care Society.

The association says that accepting money from a medical cannabis company is analogous to receiving funding from the pharmaceutical industry, and that all research will be peer-reviewed and administered at arms-length from the company, unrestricted.

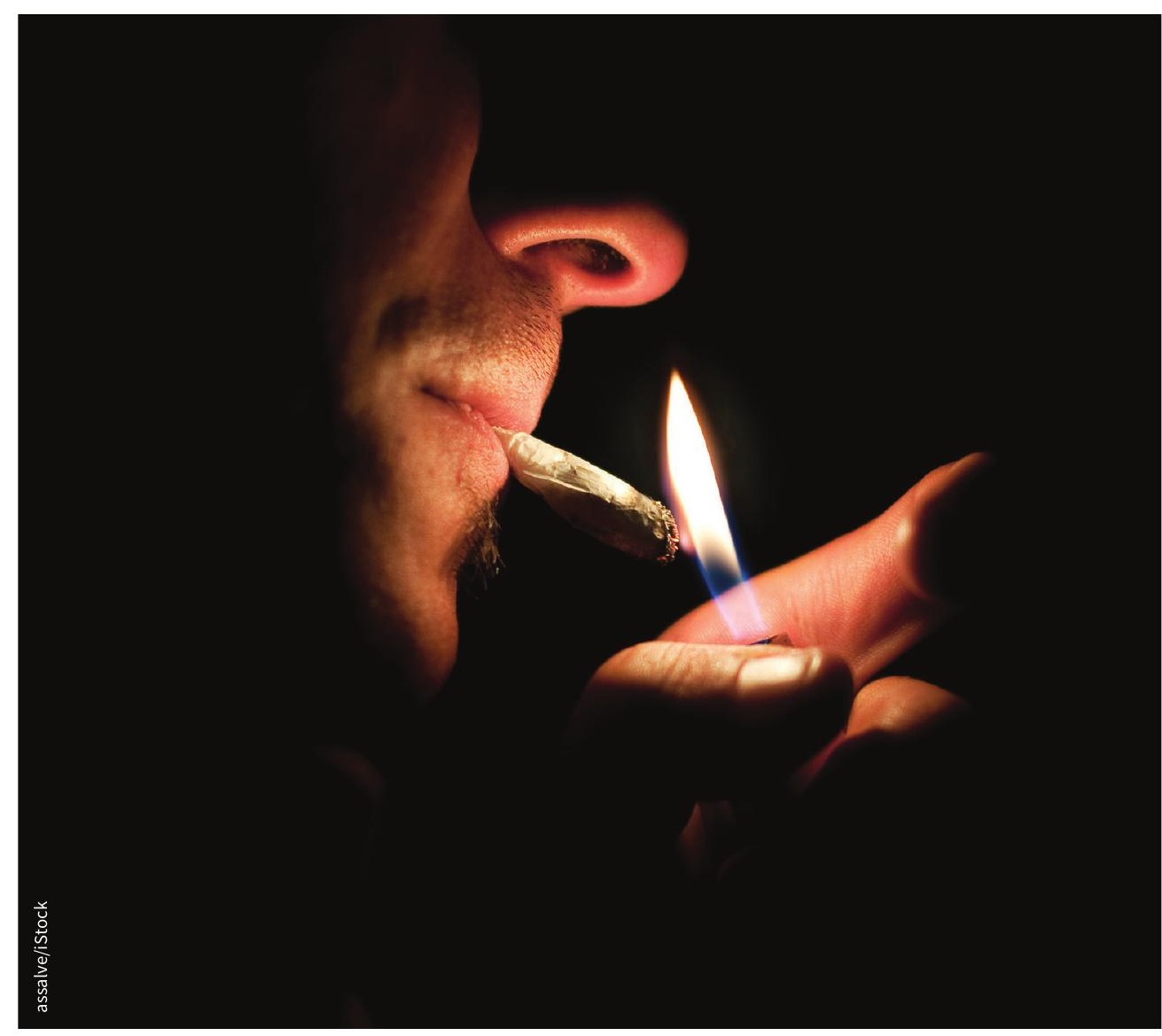

Some health experts say you don't need research to know inhaling cannabis smoke is bad for your lungs.

The research funded by Tetra will focus on the effects of smoking cannabis on lung health and function for patients seeking relief from cancer pain. "If the patient survives cancer, what are the long-term risks?" said Guy Chamberland, chief executive of Tetra. However, he added, it is not appropriate for the company to seek answers for such questions itself as it would appear biased.

Parraga, though, is not convinced the work is necessary. "We don't need more research to know that smoking is bad for your lungs," she said. Studies on edibles and other non-smoked forms of cannabis would be more acceptable, she added.

She also notes that work with a cannabis company might end up unpublishable anyway. The tobacco industry is buying up cannabis companies, which would exclude them from most scientific collaborations. The Lung Association says it will not accept funding from an entity owned by a tobacco company. Scientific societies - including the Canadian Thoracic Society, the American Thoracic Society 
and the European Respiratory Society are drawing up their positions on cannabis research, which Parraga expects will result in similar restrictions to the ones they have on tobacco.

Other charities and academic institutions are grappling with the same issue, as legalization expands both the number of people using cannabis and the potential sources of funding for research. "We've spent a lot of time talking about it," said Siân Bevan, chief science officer for the Arthritis Society. Although the society doesn't have partnerships with cannabis companies, it is not ruling them out, provided they comply with its rules on independence and transparency.
The Michael G. DeGroot Centre for Medicinal Cannabis Research at McMaster University doesn't accept industry funding to support central operations, but faculty are free to partner with companies on specific projects, if they meet the university's and centre's standards for transparency and dissemination, especially for negative results. "This is an evolving landscape with a substantive industry," said James Mackillop, the centre's director. "We don't want to be an ostrich with our head in the sand and not interface with that industry."

Tobacco companies have a long history of introducing bias into research and misleading people about the risks of smoking, making it easy to refuse collaboration, but the same is not necessarily true of the cannabis industry, according to Mackillop. "There is a long list of reasons to be cautious, but it doesn't make sense to have a clear bright line," he said. "We should decide on a case-bycase basis."

Parraga, though, is not convinced industry partnerships are needed to fund the necessary research, at least on smoked cannabis. "We have big federal and provincial funding agencies," she said. "There are pathways to be funded that don't involve companies."

Brian Owens, St. Stephen, NB 